\title{
Protective role of frizzled-related protein B on matrix metalloproteinase induction in mouse chondrocytes
}

\author{
Carole Bougault ${ }^{1 \dagger}$, Sabrina Priam ${ }^{1 \dagger}$, Xavier Houard ${ }^{1}$, Audrey Pigenet ${ }^{1}$, Laure Sudre ${ }^{1}$, Rik J Lories ${ }^{2}$, \\ Claire Jacques ${ }^{1}$ and Francis Berenbaum ${ }^{1,3,4^{*}}$
}

\begin{abstract}
Introduction: Our objective was to investigate whether a lack of frizzled-related protein B (FrzB), an extracellular antagonist of the Wnt signaling pathways, could enhance cartilage degradation by facilitating the expression, release and activation of matrix metalloproteinases (MMPs) by chondrocytes in response to tissue-damaging stimuli.

Methods: Cartilage explants from $\mathrm{FrzB}^{-/-}$and wild-type mice were challenged by excessive dynamic compression ( $0.5 \mathrm{~Hz}$ and $1 \mathrm{MPa}$ for 6 hours). Load-induced glycosaminoglycan (GAG) release and MMP enzymatic activity were assessed. Interleukin-1 $\beta$ (IL-1 $\beta)(10,100$ and 1000 pg/mL for 24 hours) was used to stimulate primary cultures of articular chondrocytes from $\mathrm{FrzB}^{-/-}$and wild-type mice. The expression and release of MMP-3 and -13 were determined by RT-PCR, western blot and ELISA. The accumulation of $\beta$-catenin was assessed by RT-PCR and western blot.

Results: Cartilage degradation, as revealed by a significant increase in GAG release (2.8-fold, $P=0.014$ ) and MMP activity (4.5-fold, $P=0.014$ ) by explants, was induced by an excessive load. Load-induced MMP activity appeared to be enhanced in $\mathrm{FrzB}^{-1-}$ cartilage explants compared to wild-type $(P=0.17)$. IL-1 $\beta$ dose-dependently induced Mmp-13 and -3 gene expression and protein release by cultured chondrocytes. IL-1 $\beta$-mediated increase in MMP-13 and -3 was slightly enhanced in $\mathrm{FrzB}^{-/-}$chondrocytes compared to wild-type $(P=0.05$ and $P=0.10$ at gene level, $P=0.17$ and $P=0.10$ at protein level, respectively). Analysis of $C \operatorname{tnn} 1 b$ and Lef1 gene expression and $\beta$-catenin accumulation at protein level suggests that the enhanced catabolic response of $\mathrm{FrzB}^{-1-}$ chondrocytes to $\mathrm{IL}-1 \beta$ and load may be associated with an over-stimulation of the canonical Wnt/ß-catenin pathway.
\end{abstract}

Conclusions: Our results suggest that FrzB may have a protective role on cartilage degradation and MMP induction in mouse chondrocytes by attenuating deleterious effects of the activation of the canonical Wnt/ $\beta$-catenin pathway.

\section{Introduction}

Osteoarthritis $(\mathrm{OA})$ is a common multifactorial joint disease, with ageing and excessive loading as important risk factors. Although the pathophysiology of OA involves cartilage, bone and the synovial tissue, the main feature of $\mathrm{OA}$ remains the progressive degradation of articular cartilage. Progressive joint destruction in $\mathrm{OA}$ has been associated

\footnotetext{
* Correspondence: francis.berenbaum@sat.aphp.fr

${ }^{\dagger}$ Equal contributors

'INSERM UMRS 938, UPMC, Univ Paris 06, Faculté de Médecine Pierre \& Marie Curie Paris VI, Hôpital Saint-Antoine, AP-HP, 184 rue du Faubourg Saint-Antoine, Paris 75012, France

${ }^{3}$ Department of Rheumatology, Assistance Publique - Hôpitaux de Paris, Saint-Antoine Hospital, 184 rue du Faubourg Saint-Antoine, Paris 75012, France

Full list of author information is available at the end of the article
}

with overactivation of Wnt signaling in numerous studies [1-6]. The Wnt signaling pathway is a potent regulator of bone and cartilage homeostasis and also has a role in human joint diseases $[7,8]$. The canonical Wnt pathway is initiated by binding of Wnt ligands to frizzled receptors and co-receptors, low-density lipoprotein receptors (LRP-5/6), which leads to intracellular $\beta$-catenin stabilization and accumulation, nuclear translocation, interaction with transcription factors, T-cell factor and lymphoid enhancer binding factor (LEF), and, finally, activation of target genes. The noncanonical Wnt pathways involve specific ligands and are independent of $\beta$-catenin and LRPs. Wnt ligands such as Wnt-7b, Wnt-16 and the Wnt target gene Wnt-1 inducible signaling pathway protein 1 (Wisp-1) were found upregulated in OA cartilage [1-3]. In addition, $\beta$-catenin, 
the co-receptor LRP-5 and the transcription factor LEF-1 were found overexpressed [4-6]. Frizzled-related protein B (FrzB) is an extracellular antagonist of the Wnt signaling pathway, also called secreted Frizzled-related protein 3 (sFRP-3). As FrzB can bind Wnts in the extracellular space and prevent ligand-receptor interaction, the protein can be considered an antagonist of both canonical and noncanonical signaling. Two single-nucleotide polymorphisms in $F R Z B$, which are loss-of-function mutations, were associated with an increased risk of OA [9-13]. However, this association was challenged by recent studies [14-17], so the potential role of FrzB in OA is still controversial.

Studies in mouse models of OA corroborated the association between cartilage degradation and an overactivation of Wnt signaling. In particular, Wisp-1 was found upregulated in two models of $\mathrm{OA}$; moreover, local overexpression of Wisp-1 enhanced cartilage damage [3]. Transgenic mice that produced activated- $\beta$-catenin in adult chondrocytes developed an OA-like phenotype upon ageing [4]. FrzB ${ }^{-/}$ knockout mice did not develop spontaneous OA, but the deletion of $\operatorname{FrzB}$ increased cartilage loss in three different models of arthritis [18]. FrzB may thus have a protective role on OA progression. How FrzB can influence OA process remains largely unclear, but various hypotheses have been suggested [4,18-22]. The canonical Wnt pathway is crucial for proper chondrocyte differentiation in early developmental processes to control chondrogenesis and, later, to regulate hypertrophic maturation. Abnormal Wnt signaling in the absence of FrzB could cause aberrant skeletal morphogenesis, and variations in human hip shape have been associated with the abovementioned FrzB polymorphisms [19]. This signaling could contribute to the development of OA by increasing the biomechanical burden on the articular cartilage $[19,23]$. In addition, OA is also characterized by hypertrophy-like changes in chondrocytes, which could be enhanced by an overactivation of Wnt signaling in absence of FrzB [24].

In cultured chondrocytes, Wnt-3a - a commonly used Wnt ligand that triggers $\beta$-catenin signaling - increased the expression of matrix metalloproteinase (MMP)-3 and MMP-13, and MMP-2 and MMP-9 enzymatic activities [25-27]. In transgenic mice, activated $\beta$-catenin increases the expression of MMP-2, MMP-3, MMP-7, MMP-9 and MMP-13 [4,28]. Similarly, downregulation of LRP-5 decreased the expression of MMP-7, MMP-9, MMP-13 and MMP-14 [5,6]. The transcription complex formed by activated- $\beta$-catenin and Lef- 1 has been shown to strongly bind MMP-9, MMP-13 and MMP-14 promoters, especially $[5,29]$.

We focused on the hypothesis that the absence of FrzB could favor OA-like catabolic processes in cartilage by increasing the activation of the Wnt signaling pathway. We therefore studied cartilage degradation in FrzB KO mice, after biomechanical loading or cytokine treatment.

\section{Methods}

Animals

All experiments were made on explants or primary chondrocytes extracted from 3-day-old to 6-day-old newborn litters from $\mathrm{FrzB}^{-/-}$or wild-type mice [18]. All procedures were in accordance with the European Directive N886/ 609 and were performed according to the protocols approved by French and European ethics committees for animal use and care (Comité Régional d'Ethique en Expérimentation Animale $N^{\circ} 3$ de la région Ile de France).

\section{Compression of costal cartilage explants}

The procedure for compressive loading of mouse costal cartilage explants was as described previously [30]. Briefly, explants were harvested from rib cages of 4-day-old to 6day-old newborn mice. Samples were cleaned, divided into segments, pooled and weighed for further normalization; each sample consisted of around 30 to $40 \mathrm{mg}$ costal cartilage. The explants were allowed to rest for about 20 hours in $3 \mathrm{ml}$ serum-free medium (Dulbecco's modified Eagle's medium supplemented with $0.1 \%$ bovine serum albumin and $30 \mathrm{mM}$ Hepes). They were washed before they underwent 6-hour dynamic compression in $1.5 \mathrm{ml}$ of the same fresh medium (sinusoidal wave-form 0 to $1 \mathrm{MPa}$ at $0.5 \mathrm{~Hz}$ ) by the Biopress system (Flexercell International, Dunn Labortechnick GmbH, Asbach, Germany). Control explants were kept in unloaded conditions. After the application of the mechanical regimen, supernatants and cartilage explants were collected and stored immediately at $-80^{\circ} \mathrm{C}$. Our results are expressed as fold-induction versus the uncompressed explant controls.

\section{Primary culture of mouse articular chondrocytes}

Primary chondrocytes were isolated from articular cartilage of 4-day-old to 6-day-old newborn mice as described previously [31]. After 1 week of expansion, the cells were placed in serum-free conditions for 24 hours $(0.1 \%$ bovine serum albumin; Sigma Aldrich, Saint-Quentin Fallavier, France) and then treated for 24 hours in serum-free medium supplemented with $0,10,100$ or $1,000 \mathrm{pg} / \mathrm{ml}$ interleukin (IL)-1 $\beta$ (PeproTech, Tebu-Bio, Le Perray-enYvelines, France). Our results are expressed as foldinduction versus the nontreated controls.

\section{RNA extraction, reverse transcription and real-time polymerase chain reaction}

RNA was extracted from chondrocytes cultured with and without IL-1 $\beta$ by use of the RNeasy minikit (Qiagen, Courtaboeuf, France); for the RNA extraction from compressed and uncompressed cartilage explants, Proteinase K (Qiagen) was first added to remove proteins as suggested for tissue samples by the manufacturer. Reverse transcription was performed on $1 \mu \mathrm{g}$ RNA for monolayer cultured cells and on 100 to 200 ng RNA for explants 
using the Omniscript kit (Qiagen). Relative quantification of genes involved use of the LC480 LightCycler Real Time PCR system (Roche Applied Science, Meylan, France) and the Go Taq QPCR master mix (Promega, Charbonnières les Bains, France). mRNA levels of MMP-3 and MMP-13, $\beta$-catenin (Ctnnb1) and Lef1 were normalized to that of hypoxanthine-guanine phosphoribosyltransferase (Hprt), used as the internal standard.

The primes used (sense and antisense) were as follows: $M m p-3$, s-TGAAAATGAAGGGTCTTCCGG and as-GCAGAAGCTCCATACCAGCA; $M m p$-13, s-GATGG CACTGCTGACATCAT and as-TGTAGCCTTTGGAAC TGCTT; Ctnnb1, s-GCAGCAGCAGTTTGTGGA and as-TGTGGAGAGCTCCAGTACACC; Lef1, s-TCCTGAA ATCCCCACCTTCT and as-TGGGATAAACAGGCTG ACCT; and Hprt, s-AGGACCTCTCGAAGTGT and asATTCAAATCCCTGAAGTACTCAT.

\section{MMP-3 and MMP-13 protein measurement}

The amount of MMP-3 and MMP-13 released by chondrocytes in response to IL-1 $\beta$ was assessed in the culture supernatants. For total mouse MMP-3 secretion we used a commercially available enzyme-linked immunosorbent assay kit (R\&D Systems, Lille, France). For total mouse MMP-13 secretion we performed western blot analysis as described previously [32] with rabbit polyclonal antibody for MMP-13 (H-230; Santa Cruz Biotechnology, Tebu-Bio). Densitometry analysis of immunoblots involved use of Multi Gauge software (Fujifilm, Paris, France).

\section{Glycosaminoglycan and matrix metalloproteinase enzymatic activity assays}

The amount of glycosaminoglycan and global MMP activity was measured in the culture supernatants of compressed cartilage explants. Released glycosaminoglycan was assessed by reaction with dimethylmethylene blue [33]. Shark chondroitin sulfate was used as a standard. MMP activity was assessed by Mca-Pro-Leu-Gly-Leu-Dpa-AlaArg- $\mathrm{NH}_{2}$ synthetic fluorogenic substrate (Bachem, Weil am Rhein, Germany) in continuous assays [34]. Results were normalized to milligram wet weight cartilage and concentration of proteins in the culture supernatant.

\section{$\beta$-Catenin accumulation}

Intracellular proteins were extracted from chondrocytes cultured with and without IL-1 $\beta$. Assay of total mouse $\beta$-catenin involved western blot analysis with rabbit polyclonal antibody for $\beta$-catenin (Cell Signaling, Danvers, MA, USA). A reprobing with anti- $\beta$-actin antibodies (AC-15; Sigma Aldrich) served as a loading control. Densitometry analysis of immunoblots involved use of Multi Gauge software (Fujifilm). The ratio of $\beta$ catenin band intensity to the $\beta$-actin band intensity was calculated.

\section{Statistical analysis}

Data are expressed as the mean \pm standard error of the mean and were analyzed by the use of Mann-Whitney nonparametric tests. Three to four independent experiments were performed. $P$ values and number of experiments $(n)$ are indicated in the figure legends.

\section{Results}

Load-induced catabolism is enhanced in $\mathrm{FrzB}^{-/-}$cartilage Cartilage explants from $\mathrm{FrzB}^{-/-}$and wild-type mice were stimulated by dynamic compression for 6 hours. As previously published by our group, load induced cartilage degradation in the explants [35]. Cartilage degradation was revealed by a net increase in glycosaminoglycan release (2.8-fold, $P=0.014$; Figure $1 \mathrm{~A}$ ) and MMP activity (4.5-fold, $P=0.014$; Figure $1 \mathrm{~B})$. At baseline, cartilage degradation was not different between the $\mathrm{FrzB}^{-/-}$and wild-type samples (data not shown). Load-induced glycosaminoglycan release was similar in FrzB ${ }^{-/}$and wild-type samples but loadinduced increase in MMP activity was slightly enhanced in FrzB $^{-/-}$cartilage explants compared with wild-type explants (1.6-fold, $P=0.17$; Figure $1 B$ ). The lack of FrzB thus tends to enhance the catabolic response of chondrocytes in situ, in response to mechanical stress.

\section{IL-1 $\beta$-mediated MMP induction is enhanced in FrzB $^{-/-}$chondrocytes}

Primary cultures of articular chondrocytes from FrzB ${ }^{-/-}$ and wild-type mice were stimulated with increasing doses of IL- $1 \beta$ for 24 hours (10, 100 and $1000 \mathrm{pg} / \mathrm{ml})$. IL-1 $\beta$ dose-dependently induced $M m p-13$ gene expression (up to 15 -fold, $P=0.05$; Figure $2 \mathrm{~A}$ ). At the higher dose, IL-1 $\beta$ induced $M m p-13$ gene expression was enhanced in $\mathrm{FrzB}^{-/-}$ chondrocytes compared with wild-type chondrocytes $(P=$ 0.05). Of note, in basal conditions $M m p-13$ gene expression was similar in FrzB ${ }^{-/-}$and wild-type chondrocytes $(0.012 \pm 0.008$ vs. $0.020 \pm 0.008$ arbitrary units, respectively). At protein level, MMP-13 release was measured by western blot analysis (Figure 2B). MMP-13 release was not modulated by the lower doses of IL- $1 \beta$, but was significantly increased in response to $1,000 \mathrm{pg} / \mathrm{ml}(P=0.014)$. This increase in MMP-13 release tended to be slightly enhanced in $\mathrm{FrzB}^{-/-}$chondrocytes compared with wildtype chondrocytes $(1.5$-fold, $P=0.17)$. Similarly, IL-1 $\beta$ dose-dependently induced $M m p-3$ gene expression (up to 500 -fold, $P=0.05$; Figure $3 \mathrm{~A}$ ). At the higher dose, IL-1 $\beta$ induced $M m p-3$ gene expression tended to be enhanced in $\mathrm{FrzB}^{-/-}$chondrocytes compared with wild-type chondrocytes $(P=0.10)$. As for $M m p-13, M m p-3$ gene expression was similar in $\mathrm{FrzB}^{-/-}$and wild-type chondrocytes in basal conditions $(0.0021 \pm 0.0010$ vs. $0.0017 \pm 0.0004$ arbitrary units, respectively). At protein level, MMP-3 release was assessed by enzyme-linked immunosorbent assay (Figure 3B). MMP-3 was not detected in untreated 

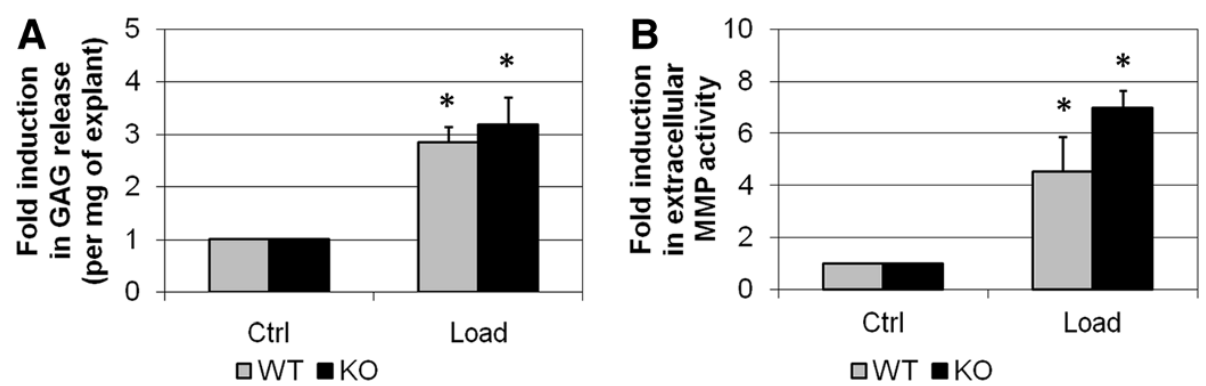

Figure 1 Load-induced glycosaminoglycan release and matrix metalloproteinase activity in mouse cartilage explants from FrzB ${ }^{-/-}$and wild-type mice. Explants were subjected to dynamic compression for 6 hours $(0.5 \mathrm{~Hz}, 1 \mathrm{MPa})$. FrzB ${ }^{-1-}$ cartilage explants (black bars, $\left.n=4\right)$ or wild-type $(\mathrm{WT})$ explants (gray bars, $n=4$ ) were loaded. Results from the loaded cartilage explants were normalized to those from the corresponding nonloaded explants (Ctrl), so that the graphs represent the fold-induction in response to compression. (A) Amount of glycosaminoglycan (GAG) released from cartilage explants into culture supernatant. (B) Matrix metalloproteinase (MMP) enzymatic activity was measured in the culture supernatant of cartilage explants. Load-induced MMP activity tends to be enhanced in FrzB ${ }^{-/-}$explants compared with WT $(P=0.17)$. Bars represent the mean \pm standard error of the mean. ${ }^{*} P \leq 0.05$ versus $\mathrm{Ctrl}$. FrzB, frizzled-related protein $\mathrm{B} ; \mathrm{KO}$, knockout.

conditions, but only in response to the higher doses of IL$1 \beta(P=0.05)$. MMP-3 release in response to $100 \mathrm{pg} / \mathrm{ml} \mathrm{IL-}$ $1 \beta$ was enhanced in $\mathrm{FrzB}^{-/-}$chondrocytes compared with wild-type $(2.1$-fold, $P=0.10)$. The absence of FrzB thus tends to enhance the catabolic response of cultured chondrocytes, in response to a proinflammatory stress. These results are parallel to the enhanced catabolic response observed in loaded $\mathrm{FrzB}^{-1-}$ cartilage explants.

\section{IL-1 $\beta$-induced and load-induced catabolism in $\mathrm{FrzB}^{-/-}$ chondrocytes is associated with canonical Wnt/ $\beta$-catenin signaling}

We wondered whether the enhancement in the response of $\mathrm{FrzB}^{-1-}$ chondrocytes to IL-1 $\beta$ and load was associated with a deregulation in $\mathrm{Wnt} / \beta$-catenin signaling. In basal conditions, $C$ tnnb1 gene expression (coding $\beta$-catenin) was comparable between $\mathrm{FrzB}^{-1-}$ cultured chondrocytes and
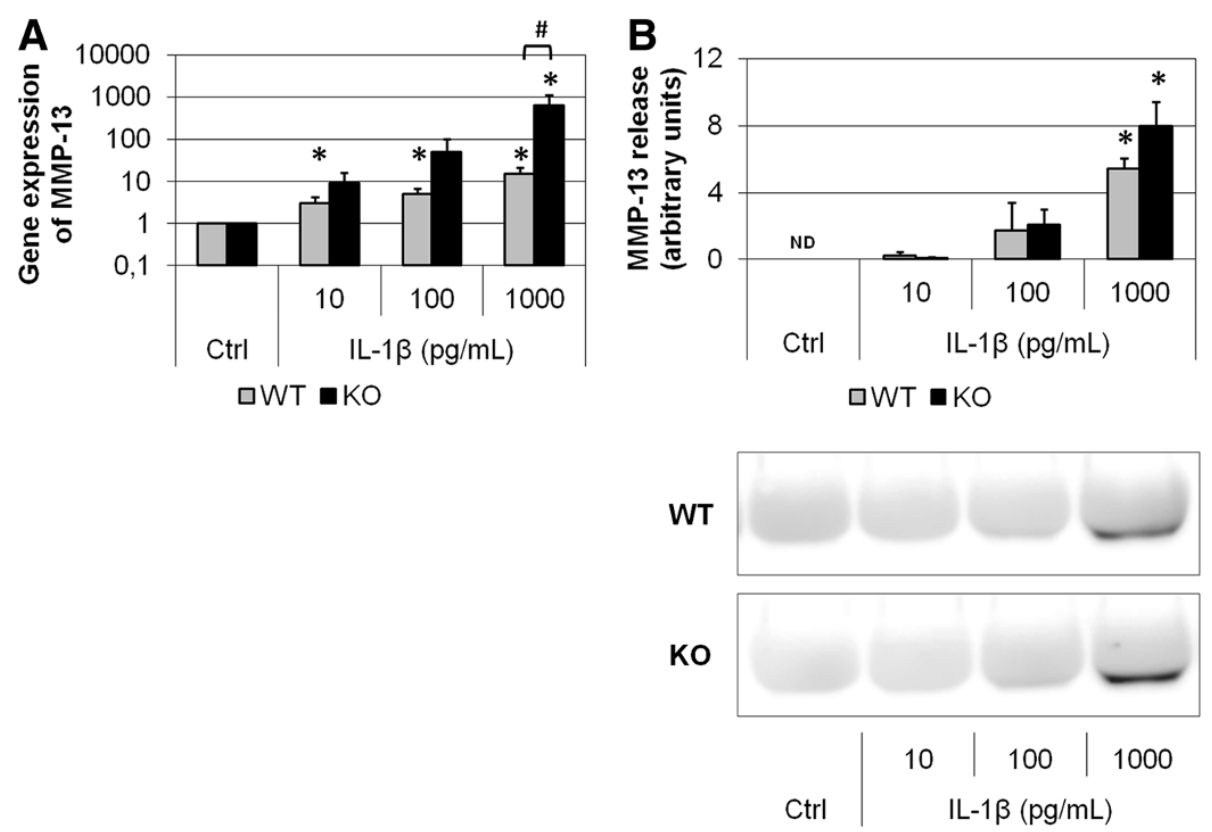

Figure 2 IL-1 $\beta$-mediated increase in MMP-13 in cultured articular chondrocytes is enhanced in absence of FrzB. Primary chondrocytes were treated for 24 hours with interleukin (IL)-1 $\beta$ (10, 100 or 1,000 pg/ml). Results from the treated chondrocytes were normalized to those from nontreated samples (Ctrl), so that the graphs represent the fold-induction in response to $\mathrm{IL}-1 \beta$. (A) Real-time polymerase chain reaction analysis of Mmp-13 gene expression. IL-1ß-induced Mmp-13 gene expression tends to be enhanced in FrzB ${ }^{-1-}$ chondrocytes compared with wild-type (WT) chondrocytes, especially with $1,000 \mathrm{pg} / \mathrm{ml}(P=0.05, \mathrm{n}=3)$. (B) Culture media were analyzed for MMP-13 by western blotting. Quantification of the MMP-13 blot is shown above the blot. IL-1 $\beta$-induced MMP-13 protein release tends to be enhanced in FrzB ${ }^{-1-}$ chondrocytes compared with WT chondrocytes, especially with $1,000 \mathrm{pg} / \mathrm{ml}(P=0.17, n=4)$. Bars represent the mean \pm standard error of the mean. ${ }^{*} P \leq 0.05$ versus $C$ trl, $\# P \leq 0.10$ between $\mathrm{FrzB}^{-/-}$and $\mathrm{WT}$. FrzB, frizzled-related protein $\mathrm{B} ; \mathrm{KO}$, knockout; MMP, matrix metalloproteinase; ND, not detected. 

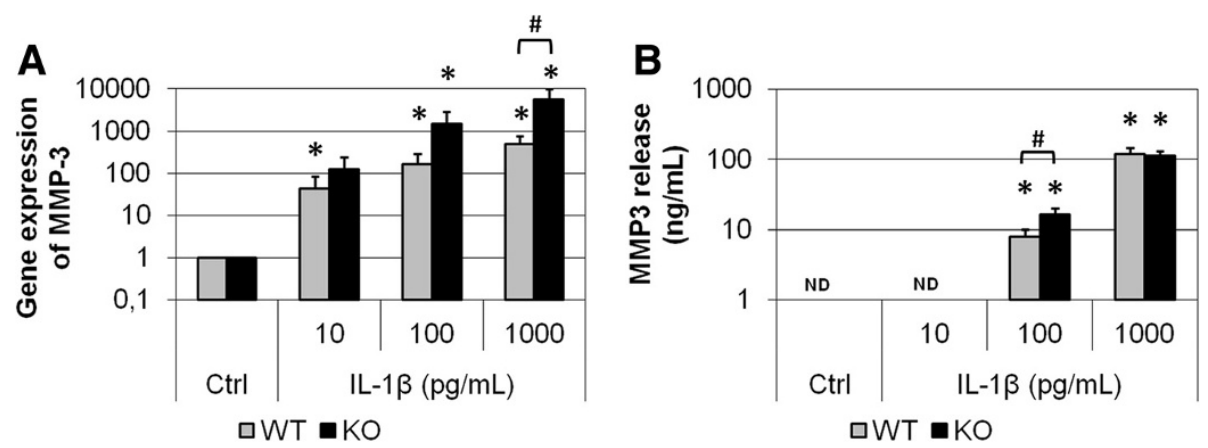

Figure $3 \mathrm{IL}-1 \beta$-mediated increase in MMP-3 in cultured articular chondrocytes is enhanced in absence of FrzB. Primary chondrocytes were treated for 24 hours with interleukin (IL)-1 1 (10, 100 or 1,000 pg/ml). (A) Real-time polymerase chain reaction analysis of Mmp-3 gene expression. Results from the treated chondrocytes were normalized to those from nontreated samples (Ctrl), so that the graphs represent the fold-induction in response to IL-1 $\beta$. The IL-1 $\beta$-induced $M m p-3$ gene expression tends to be enhanced in Frz $\mathrm{B}^{-/-}$chondrocytes compared with wild-type (WT) chondrocytes, especially with $1,000 \mathrm{pg} / \mathrm{ml}(P=0.10, n=3)$. (B) Culture media were analyzed for total MMP-3 by enzyme-linked immunosorbent assay. MMP-3 protein release in response to $100 \mathrm{pg} / \mathrm{ml} \mathrm{IL-1 \beta}$ tends to be enhanced in FrzB ${ }^{-/-}$chondrocytes compared with WT chondrocytes $(P=0.10, n=3)$. Bars represent the mean \pm standard error of the mean. ${ }^{*} P \leq 0.05$ versus $C$ trl, $\# P \leq 0.10$ between FrzB ${ }^{-/-}$and WT. FrzB, frizzled-related protein $B ; \mathrm{KO}$, knockout; MMP, matrix metalloproteinase; ND, not detected.
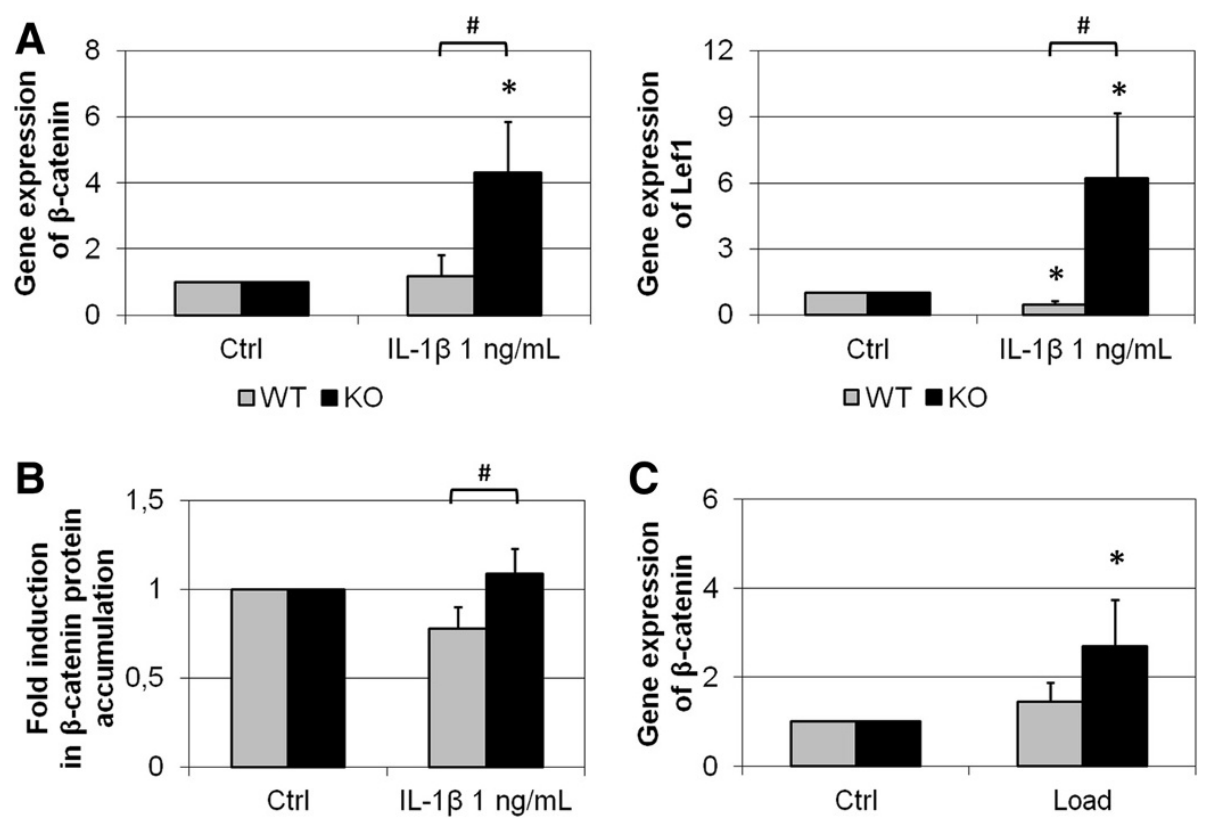

Figure 4 IL-1 $\beta$-mediated and load-mediated regulation of $\mathrm{Wnt} / \beta$-catenin signaling in chondrocytes from FrzB ${ }^{-/-}$and wild-type mice. Cultured articular chondrocytes from $\mathrm{FrzB}^{-/-}$mice or wild-type (WT) mice were treated for 24 hours with interleukin (IL)-1 $\beta$ (1 ng/ml). Results from the IL-1 $\beta$-treated samples were normalized to the control ones (Ctrl), so that the graphs represent the fold-induction in response to IL-1 $\beta$. (A) Ctnnb1 gene expression (coding $\beta$-catenin) and Lef1 gene expression (a Wnt/ $\beta$-catenin target gene) were analyzed by real-time polymerase chain reaction (PCR; $n=4$ and $n=3$, respectively). Ctnnb1 gene expression was not modulated by LL-1 $\beta$ in WT chondrocytes and Lef1 gene expression was decreased $(P=0.05)$. In contrast, the treatment induced Ctnnb1 and Lef1 gene expression in FrzB ${ }^{-/-}$chondrocytes $(P=0.014$ and $P=0.05$, respectively). IL-1 $\beta$-mediated regulation of $\beta$-catenin expression was thus different between $\mathrm{FrzB}^{-/-}$and WT $(P=0.057$ for Ctnnb1, $P=0.05$ for Lef1). (B) Intracellular extracts were analyzed for total $\beta$-catenin by western blotting. Quantification of $\beta$-catenin blot suggested that IL-1 $\beta$-mediated $\beta$-catenin accumulation was different between $\mathrm{FrzB}^{-/-}$and WT $(P=0.10, n=4)$. (C) FrzB ${ }^{-/-}$cartilage explants or WT explants were subjected to dynamic compression for 6 hours $(0.5 \mathrm{~Hz}, 1 \mathrm{MPa})$. Ctnnb1 gene expression was analyzed by real-time PCR $(n=3)$. Results from the loaded cartilage explants were normalized to those from the corresponding nonloaded explants (Ctrl), so that the graphs represent the fold-induction in response to compression. Ctnnb1 gene expression was not affected by load in WT explants but was increased 2.7 fold in compressed FrzB ${ }^{-1-}$ samples $(P=0.05)$. The load-induced increase in $C$ tnnb 1 mRNA tends to be enhanced in $\mathrm{FrzB}^{-/-}$explants compared with WT explants $(P=0.20)$. Bars represent the mean \pm standard error of the mean, ${ }^{*} P \leq 0.05$ versus $C$ trl, $\# P \leq$ 0.10 between $\mathrm{FrzB}^{-/-}$and WT. FrzB, frizzled-related protein $\mathrm{B} ; \mathrm{KO}$, knockout. 
wild-type chondrocytes $(0.62 \pm 0.22$ vs. $0.95 \pm 0.12$ arbitrary units, respectively). Of note, similar results were observed for the Wnt/B-catenin target gene Lef1 $(0.031 \pm 0.009$ for wild-type chondrocytes vs. $0.018 \pm 0.013$ for $\mathrm{FrzB}^{-/-}$chondrocytes). These data are in accordance with the previous transcriptome analysis of the bone-cartilage unit of $\mathrm{FrzB}^{-/-}$ mice: at baseline in vivo, the Ctnnb1 mRNA level was not different between the $\mathrm{FrzB}^{-/-}$and wild-type strains [36].

$C t n n b 1$ gene expression was not affected by IL-1 $\beta$ in wild-type cultured chondrocytes (Figure 4A). In IL-1 $\beta$ treated $\mathrm{FrzB}^{-1-}$ chondrocytes, Ctnnb1 gene expression was induced 4.3-fold compared with untreated chondrocytes $(P=0.014)$. Ctnnb1 gene expression was thus markedly higher in IL-1 $\beta$-treated $\mathrm{FrzB}^{-/-}$chondrocytes compared with wild-type chondrocytes (3.6-fold, $P=0.057$ ). In parallel, Lef1 gene expression was induced 6.2-fold in IL-1 $\beta$ treated $\mathrm{FrzB}^{-/-}$chondrocytes compared with untreated chondrocytes $(P=0.05)$ and the Lef1 mRNA level was clearly higher in IL-1 $\beta$-treated FrzB ${ }^{-1-}$ chondrocytes compared with wild-type chondrocytes (13-fold, $P=0.05$; Figure 4A). Analysis of $\beta$-catenin accumulation at the protein level did not strictly correlate this transcriptional regulation (Figure 4B). IL-1 $\beta$ tended to decrease the $\beta$ catenin content of wild-type cultured chondrocytes $(20 \%$ less, $P=0.057$ ), whereas no modulation was observed in $\mathrm{FrzB}^{-/-}$chondrocytes. The $\beta$-catenin content was thus higher in IL-1 $\beta$-treated $\mathrm{FrzB}^{-1-}$ chondrocytes compared with wild-type chondrocytes (1.4-fold, $P=0.10$ ). IL-1 $\beta$ only slightly modulates $\mathrm{Wnt} / \beta$-catenin signaling in our model, but FrzB-dependent deregulation was observed in IL-1 $\beta$-treated chondrocytes.

Concerning the catabolic response of $\mathrm{FrzB}^{-/-}$cartilage to load, analysis of Ctnnb1 gene expression showed very similar results (Figure 4C). The Ctnnb1 mRNA level was not affected by compression in wild-type explants. In compressed $\mathrm{FrzB}^{-/-}$samples, Ctnnb1 gene expression was induced 2.7-fold compared with uncompressed samples $(P=0.05)$. The modulation in $\mathrm{Wnt} / \beta$-catenin signaling in response to load was thus slightly enhanced in FrzB $^{-/-}$cartilage $(P=0.20$; Figure $4 C)$.

Overall, these results suggest that the enhancement in the response of $\mathrm{FrzB}^{-/-}$chondrocytes to IL- $1 \beta$ and load may be associated with an overstimulation of the canonical Wnt pathway.

\section{Discussion}

Enhanced responsiveness to mechanical stress in the absence of FrzB and involvement of the canonical Wnt/ $\beta$-catenin pathway

We have demonstrated that load-induced MMP activity was enhanced in $\mathrm{FrzB}^{-/-}$cartilage explants. In addition, load stimulated Ctnnb1 gene expression in $\mathrm{FrzB}^{-/-}$explants. These results suggest that the load-induced catabolic response of chondrocytes may be in part mediated by the canonical Wnt pathway. The involvement of Wnt signaling in osteoblast responsiveness to mechanical stimulation was proven in various studies [37-42]. In particular, TOPGAL reporter mice showed that the canonical Wnt/Bcatenin pathway was activated by mechanical stress in vivo and in cultured osteoblasts [43]. Furthermore, increasing basal $\beta$-catenin levels was shown to enhance the effects of mechanical stress [44]. Chondrocyte responses towards mechanical stimulation have been less studied. However, pressure-induced mechanical stress triggered $\beta$-catenin tyrosine phosphorylation in cultured chondrocytes [45], thereby probably releasing the molecule from adherens junctions and increasing its availability for intracellular signaling. Partial $\beta$-catenin nuclear translocation was also observed in response to tensile strain [27]. Furthermore, there was an additive effect of load and Wnt-3a on $\beta$ catenin translocation and on upregulation of $M m p-3$ gene expression [27]. Of interest, a downregulation of FrzB was observed in human and mouse cartilage explants in response to mechanical injury, suggesting a de-repression of the canonical Wnt pathway [46]. Wnt/ß-catenin signaling may thus be part of the signaling response leading to excessive catabolism and cartilage degradation in response to abnormal loading and FrzB may have a protective role on load-induced increase in MMP activity.

\section{Enhanced responsiveness to IL-1 $\beta$ in the absence of FrzB} and involvement of the canonical Wnt/ $\beta$-catenin pathway We demonstrated that IL-1 $\beta$-mediated increases in $M m p$ 3 and Mmp-13 gene expression and protein release were enhanced in $\mathrm{FrzB}^{-1-}$ chondrocytes. Similarly, IL-1 $\beta$ stimulated Ctnnb1 and Lef1 gene expression and $\beta$-catenin accumulation in $\mathrm{FrzB}^{-/-}$chondrocytes. Canonical Wnt pathway activation may thus enhance chondrocyte responsiveness to IL-1 $\beta$. These results suggest a crosstalk between the canonical Wnt pathway, which includes $\beta$-catenin and FrzB, and the IL-1 pathway, which stimulates MMP expression in chondrocytes. In accordance with our results, activation of $\beta$-catenin signaling in cultured chondrocytes by Wnt-3a treatment potentiated IL-1 $\beta$-mediated loss of proteoglycans [25]. Conversely, inhibition of $\beta$-catenin signaling by the use of Lef1 siRNA downregulated IL-1 $\beta$-mediated increase in $M m p-13$ gene expression [29]. Sost, a biologically active inhibitor of $\beta$-catenin signaling in chondrocytes, downregulated the IL- $1 \alpha$-mediated increase in $M m p-13$ gene expression in cartilage explants and also reduced the loss of proteoglycans [47]. An alternative suggestion is that IL-1 $\beta$ treatment may induce production of canonical Wnt such as Wnt-7b, which in turn would activate $\beta$-catenin signaling [48]. In surprising contrast, in human chondrocytes $\beta$-catenin signaling was found to counteract IL- $1 \beta$ mediated increase in MMP-3 and MMP-13 expressions [48]. In conclusion, the canonical Wnt pathway may be part of mechanisms leading to excessive catabolism in 
response to inflammatory stress and FrzB may have a protective role on IL-1-mediated increase in MMP expression in mouse chondrocytes.

\section{Putative protective role of FrzB in osteoarthritis progression}

In OA, cartilage breakdown is due to cleavage of matrix molecules in response to abnormal mechanical stress and to some degree of inflammation. Because our results suggest that FrzB may have a protective role on load-mediated and IL-1-mediated catabolic processes in mouse chondrocytes, we speculate that FrzB may have a protective role in OA. Our results are consistent with the increased cartilage loss observed in models of arthritis in FrzB ${ }^{-/-}$knockout mice [18]. Moreover, gene expression of $M m p-3$ was upregulated in the cartilage of $\mathrm{FrzB}^{-/-}$mice with mBSAinduced arthritis compared with wild-type mice. However, $\mathrm{FrzB}^{-/-}$knockout mice did not develop spontaneous OA, and they did not show aberrant $M m p$ gene expressions in basal conditions, except for a twofold increase for MMP-3 [36]. FrzB may thus be involved in $\mathrm{OA}$ progression rather than OA onset. Although FrzB may interact directly with MMP-3 [18], its protective role is probably linked with a deregulation of the Wnt pathways. The recent identification of FrzB as a blocker of hypertrophic differentiation in articular cartilage [22] promotes the hypothesis of a protective role of FrzB in OA through the Wnt-mediated regulation of hypertrophic maturation.

\section{Conclusions}

Our results suggest that FrzB has a protective role on MMP induction in mouse chondrocytes. The results indicate a dual role of Wnt signaling in cartilage homeostasis, so that a controlled amount of Wnt signaling is necessary for maintenance of the articular cartilage, but an excess one is deleterious. Further investigations are needed to decipher the tight control of Wnt signaling in $\mathrm{OA}$, in particular concerning the differentiation of OA chondrocytes towards hypertrophy.

Our results also add evidence to demonstrate that the canonical Wnt/ $\beta$-catenin pathway is part of mechanisms leading to excessive catabolism and cartilage degradation in OA. However, the FrzB-dependent deregulation that we observed may involve both canonical and noncanonical Wnt signaling since FrzB is an inhibitor of both pathways. Little is known concerning the role of the noncanonical Wnt pathway in articular cartilage homeostasis and OA development. Recent data suggested that, in excess, Wnt-5a could stimulate degradation of the mature cartilage matrix via noncanonical pathways, while promoting normal differentiation in developing cartilage [49]. Additional investigations on Wnt regulation in OA should therefore equally explore canonical and noncanonical Wnt pathways.

\section{Abbreviations}

FrzB: frizzled-related protein B (secreted frizzled-related protein 3);

IL: interleukin; LEF: Iymphoid enhancer binding factor; LRP: low-density lipoprotein receptor; MMP: matrix metalloproteinase; OA: osteoarthritis.

\section{Competing interests}

The authors declare that they have no competing interests.

\section{Authors' contributions}

$\mathrm{CB}, \mathrm{SP}, \mathrm{XH}, \mathrm{CJ}$ and FB were responsible for conception and design. CB, SP, $A P$ and $L S$ were responsible for acquisition of data. $C B, S P, X H, R J L, C J$ and $F B$ were responsible for analysis and interpretation of the data. $C B, S P$ and $A P$ were responsible for drafting of the article. $\mathrm{XH}, \mathrm{RJ}, \mathrm{CJ}$ and $\mathrm{FB}$ were responsible for critical revision of the article for important intellectual content. All authors were responsible for final approval of the article.

\section{Authors' information}

This work was supported by a grant from Fondation pour la Recherche Médicale. CB was supported by a Fondation pour la Recherche Médicale postdoctoral fellowship and by French state funds managed by the Agence Nationale de la Recherche within the Investissements d'Avenir programme under reference ANR-11-IDEX-0004-02.

\section{Author details}

${ }^{1}$ INSERM UMRS 938, UPMC, Univ Paris 06, Faculté de Médecine Pierre \& Marie Curie Paris VI, Hôpital Saint-Antoine, AP-HP, 184 rue du Faubourg Saint-Antoine, Paris 75012, France. ${ }^{2}$ Laboratory of Tissue Homeostasis and Disease, Skeletal Biology and Engineering Research Center, Department of Development and Regeneration, KU Leuven, Herestraat 49, Leuven B3000, Belgium. ${ }^{3}$ Department of Rheumatology, Assistance Publique - Hôpitaux de Paris, Saint-Antoine Hospital, 184 rue du Faubourg Saint-Antoine, Paris 75012, France. ${ }^{4}$ Inflammation-Immunopathology-Biotherapy Department (DHU i2B), 184 rue du Faubourg Saint-Antoine, Paris 75012, France.

Received: 22 November 2013 Accepted: 2 June 2014

Published: 1 July 2014

\section{References}

1. Nakamura Y, Nawata M, Wakitani S: Expression profiles and functional analyses of Wnt-related genes in human joint disorders. Am J Pathol 2005, 167:97-105.

2. Dell'accio F, De Bari C, Eltawil NM, Vanhummelen P, Pitzalis C: Identification of the molecular response of articular cartilage to injury, by microarray screening: Wnt-16 expression and signaling after injury and in osteoarthritis. Arthritis Rheum 2008, 58:1410-1421.

3. Blom AB, Brockbank SM, van Lent PL, van Beuningen HM, Geurts J, Takahashi N, van der Kraan PM, van de Loo FA, Schreurs BW, Clements K, Newham P, van den Berg WB: Involvement of the Wnt signaling pathway in experimental and human osteoarthritis: prominent role of Wnt-induced signaling protein 1. Arthritis Rheum 2009, 60:501-512.

4. Zhu M, Tang D, Wu Q, Hao S, Chen M, Xie C, Rosier RN, O'Keefe RJ, Zuscik $\mathrm{M}$, Chen D: Activation of beta-catenin signaling in articular chondrocytes leads to osteoarthritis-like phenotype in adult beta-catenin conditional activation mice. J Bone Miner Res 2009, 24:12-21.

5. Papathanasiou I, Malizos KN, Tsezou A: Bone morphogenetic protein-2-induced Wnt/beta-catenin signaling pathway activation through enhanced lowdensity-lipoprotein receptor-related protein 5 catabolic activity contributes to hypertrophy in osteoarthritic chondrocytes. Arthritis Res Ther 2012, 14:R82.

6. Papathanasiou I, Malizos KN, Tsezou A: Low-density lipoprotein receptor-related protein 5 (LRP5) expression in human osteoarthritic chondrocytes. J Orthop Res 2010, 28:348-353.

7. Monroe DG, McGee-Lawrence ME, Oursler MJ, Westendorf JJ: Update on Wnt signaling in bone cell biology and bone disease. Gene 2012, 492:1-18.

8. Chun JS, Oh H, Yang S, Park M: Wnt signaling in cartilage development and degeneration. BMB Rep 2008, 41:485-494.

9. Loughlin J, Dowling B, Chapman K, Marcelline L, Mustafa Z, Southam L, Ferreira A, Ciesielski C, Carson DA, Corr M: Functional variants within the secreted frizzled-related protein 3 gene are associated with hip osteoarthritis in females. Proc Natl Acad Sci U S A 2004, 101:9757-9762.

10. Min JL, Meulenbelt I, Riyazi N, Kloppenburg M, Houwing-Duistermaat JJ, Seymour AB, Pols HA, van Duijn CM, Slagboom PE: Association of the 
Frizzled-related protein gene with symptomatic osteoarthritis at multiple sites. Arthritis Rheum 2005, 52:1077-1080.

11. Lane NE, Lian K, Nevitt MC, Zmuda JM, Lui L, Li J, Wang J, Fontecha M, Umblas N, Rosenbach M, de Leon P, Corr M: Frizzled-related protein variants are risk factors for hip osteoarthritis. Arthritis Rheum 2006, 54:1246-1254.

12. Valdes AM, Loughlin J, Oene MV, Chapman K, Surdulescu GL, Doherty M, Spector TD: Sex and ethnic differences in the association of ASPN, CALM1, COL2A1, COMP, and FRZB with genetic susceptibility to osteoarthritis of the knee. Arthritis Rheum 2007, 56:137-146.

13. Lories RJ, Boonen S, Peeters J, de Vlam K, Luyten FP: Evidence for a differential association of the Arg200Trp single-nucleotide polymorphism in FRZB with hip osteoarthritis and osteoporosis. Rheumatology (Oxford) 2006, 45:113-114.

14. Evangelou E, Chapman K, Meulenbelt I, Karassa FB, Loughlin J, Carr A, Doherty M, Doherty S, Gomez-Reino JJ, Gonzalez A, Halldorsson BV, Hauksson VB, Hofman A, Hart DJ, Ikegawa S, Ingvarsson T, Jiang Q, Jonsdottir I, Jonsson H, Kerkhof HJ, Kloppenburg M, Lane NE, Li J, Lories RJ, van Meurs JB, Näkki A, Nevitt MC, Rodriguez-Lopez J, Shi D, Slagboom PE, et al: Large-scale analysis of association between GDF5 and FRZB variants and osteoarthritis of the hip, knee, and hand. Arthritis Rheum 2009, 60:1710-1721.

15. Snelling $\mathrm{S}$, Ferreira A, Loughlin J: Allelic expression analysis suggests that cis-acting polymorphism of FRZB expression does not contribute to osteoarthritis susceptibility. Osteoarthritis Cartilage 2007, 15:90-92.

16. Rodriguez-Lopez J, Pombo-Suarez M, Liz M, Gomez-Reino JJ, Gonzalez A: Further evidence of the role of frizzled-related protein gene polymorphisms in osteoarthritis. Ann Rheum Dis 2007, 66:1052-1055.

17. Kerkhof JM, Uitterlinden AG, Valdes AM, Hart DJ, Rivadeneira F, Jhamai M, Hofman A, Pols HA, Bierma-Zeinstra SM, Spector TD, van Meurs JB: Radiographic osteoarthritis at three joint sites and FRZB, LRP5, and LRP6 polymorphisms in two population-based cohorts. Osteoarthritis Cartilage 2008, 16:1141-1149.

18. Lories RJ, Peeters J, Bakker A, Tylzanowski P, Derese I, Schrooten J, Thomas JT, Luyten FP: Articular cartilage and biomechanical properties of the long bones in Frzb-knockout mice. Arthritis Rheum 2007, 56:4095-4103.

19. Baker-Lepain JC, Lynch JA, Parimi N, McCulloch CE, Nevitt MC, Corr M, Lane NE: Variant alleles of the Wnt antagonist FRZB are determinants of hip shape and modify the relationship between hip shape and osteoarthritis. Arthritis Rheum 2012, 64:1457-1465.

20. Bos SD, Slagboom PE, Meulenbelt I: New insights into osteoarthritis: early developmental features of an ageing-related disease. Curr Opin Rheumatol 2008, 20:553-559.

21. Wu Q, Zhu M, Rosier RN, Zuscik MJ, O'Keefe RJ, Chen D: Beta-catenin, cartilage, and osteoarthritis. Ann N Y Acad Sci 2010, 1192:344-350.

22. Leijten JC, van Blitterwijk CA, Karperien M, Emons J, van Gool S, Wit JM, Sticht C, Decker E, Rappold G, Uitterlinden A, Rappold G, Hofman A, Rivadeneira F, Scherjon S, Wit JM, van Meurs J, van Blitterswijk CA, Karperien M: GREM1, FRZB and DKK1 are key regulators of human articular cartilage homeostasis. Arthritis Rheum 2012, 2012:34535.

23. Baker-LePain JC, Lane NE: Relationship between joint shape and the development of osteoarthritis. Curr Opin Rheumatol 2010, 22:538-543.

24. van der Kraan PM, van den Berg WB: Chondrocyte hypertrophy and osteoarthritis: role in initiation and progression of cartilage degeneration? Osteoarthritis Cartilage 2012, 20:223-232.

25. Yuasa T, Otani T, Koike T, Iwamoto M, Enomoto-Iwamoto M: Wnt/beta-catenin signaling stimulates matrix catabolic genes and activity in articular chondrocytes: its possible role in joint degeneration. Lab Invest 2008, 88:264-274.

26. Oh H, Chun $\mathrm{CH}$, Chun JS: Dkk-1 expression in chondrocytes inhibits experimental osteoarthritic cartilage destruction in mice. Arthritis Rheum 2012, 64:2568-2578.

27. Thomas RS, Clarke AR, Duance VC, Blain EJ: Effects of Wnt3A and mechanical load on cartilage chondrocyte homeostasis. Arthritis Res Ther 2011, 13:R203.

28. Tamamura Y, Otani T, Kanatani N, Koyama E, Kitagaki J, Komori T, Yamada Y, Costantini F, Wakisaka S, Pacifici M, Iwamoto M, Enomoto-Iwamoto M: Developmental regulation of Wnt/beta-catenin signals is required for growth plate assembly, cartilage integrity, and endochondral ossification. J Biol Chem 2005, 280:19185-19195.

29. Yun K, Im SH: Transcriptional regulation of MMP13 by Lef1 in chondrocytes. Biochem Biophys Res Commun 2007, 364:1009-1014.

30. Gosset M, Berenbaum F, Levy A, Pigenet A, Thirion S, Saffar JL, Jacques C: Prostaglandin E2 synthesis in cartilage explants under compression: mPGES-1 is a mechanosensitive gene. Arthritis Res Ther 2006, 8:R135.
31. Gosset M, Berenbaum F, Thirion S, Jacques C: Primary culture and phenotyping of murine chondrocytes. Nat Protoc 2008, 3:1253-1260.

32. Masuko-Hongo K, Berenbaum F, Humbert L, Salvat C, Goldring MB, Thirion S: Up-regulation of microsomal prostaglandin E synthase 1 in osteoarthritic human cartilage: critical roles of the ERK-1/2 and p38 signaling pathways. Arthritis Rheum 2004, 50:2829-2838.

33. Farndale RW, Sayers CA, Barrett AJ: A direct spectrophotometric microassay for sulfated glycosaminoglycans in cartilage cultures. Connect Tissue Res 1982, 9:247-248.

34. Houard X, Monnot C, Dive V, Corvol P, Pagano M: Vascular smooth muscle cells efficiently activate a new proteinase cascade involving plasminogen and fibronectin. J Cell Biochem 2003, 88:1188-1201.

35. Bougault C, Gosset M, Houard X, Salvat C, Godmann L, Pap T, Jacques C, Berenbaum $F$ : Stress-induced cartilage degradation does not depend on the NLRP3 inflammasome in human osteoarthritis and mouse models. Arthritis Rheum 2012, 64:3972-3981.

36. Lodewyckx L, Cailotto F, Thysen S, Luyten FP, Lories RJ: Tight regulation of wingless-type signaling in the articular cartilage - subchondral bone biomechanical unit: transcriptomics in Frzb-knockout mice. Arthritis Res Ther 2012, 14:R16.

37. Robinson JA, Chatterjee-Kishore M, Yaworsky PJ, Cullen DM, Zhao W, Li C, Kharode Y, Sauter L, Babij P, Brown EL, Hill AA, Akhter MP, Johnson ML, Recker RR, Komm BS, Bex FJ: Wnt/beta-catenin signaling is a normal physiological response to mechanical loading in bone. J Bio/ Chem 2006, 281:31720-31728.

38. Armstrong VJ, Muzylak M, Sunters A, Zaman G, Saxon LK, Price JS, Lanyon LE: Wnt/beta-catenin signaling is a component of osteoblastic bone cell early responses to load-bearing and requires estrogen receptor alpha. J Biol Chem 2007, 282:20715-20727.

39. Lin C, Jiang X, Dai Z, Guo X, Weng T, Wang J, Li Y, Feng G, Gao X, He L: Sclerostin mediates bone response to mechanical unloading through antagonizing Wnt/beta-catenin signaling. J Bone Miner Res 2009, 24:1651-1661.

40. Jansen JH, Eijken M, Jahr $\mathrm{H}$, Chiba H, Verhaar JA, van Leeuwen JP, Weinans $\mathrm{H}$ : Stretch-induced inhibition of Wnt/beta-catenin signaling in mineralizing osteoblasts. J Orthop Res 2010, 28:390-396.

41. Liedert A, Wagner $L$, Seefried L, Ebert $R$, Jakob F, Ignatius A: Estrogen receptor and Wnt signaling interact to regulate early gene expression in response to mechanical strain in osteoblastic cells. Biochem Biophys Res Commun 2010, 394:755-759.

42. Tu X, Rhee Y, Condon KW, Bivi N, Allen MR, Dwyer D, Stolina M, Turner CH, Robling AG, Plotkin LI, Bellido T: Sost downregulation and local Wnt signaling are required for the osteogenic response to mechanical loading. Bone 2012, 50:209-217.

43. Hens JR, Wilson KM, Dann P, Chen X, Horowitz MC, Wysolmerski JJ: TOPGAL mice show that the canonical Wnt signaling pathway is active during bone development and growth and is activated by mechanical loading in vitro. J Bone Miner Res 2005, 20:1103-1113.

44. Case N, Ma M, Sen B, Xie Z, Gross TS, Rubin J: Beta-catenin levels influence rapid mechanical responses in osteoblasts. J Biol Chem 2008, 283:29196-29205.

45. Lee HS, Millward-Sadler SJ, Wright MO, Nuki G, Salter DM: Integrin and mechanosensitive ion channel-dependent tyrosine phosphorylation of focal adhesion proteins and beta-catenin in human articular chondrocytes after mechanical stimulation. J Bone Miner Res 2000, 15:1501-1509.

46. Dell'Accio F, De Bari C, El Tawil NM, Barone F, Mitsiadis TA, O'Dowd J, Pitzalis C: Activation of WNT and BMP signaling in adult human articular cartilage following mechanical injury. Arthritis Res Ther 2006, 8:R139.

47. Chan BY, Fuller ES, Russell AK, Smith SM, Smith MM, Jackson MT, Cake MA, Read RA, Bateman JF, Sambrook PN, Little CB: Increased chondrocyte sclerostin may protect against cartilage degradation in osteoarthritis. Osteoarthritis Cartilage 2011, 19:874-885

48. Ma B, van Blitterswijk CA, Karperien M: A Wnt/beta-catenin negative feedback loop inhibits interleukin-1-induced matrix metalloproteinase expression in human articular chondrocytes. Arthritis Rheum 2012, 64:2589-2600.

49. Hosseini-Farahabadi S, Geetha-Loganathan P, Fu K, Nimmagadda S, Yang HJ, Richman JM: Dual functions for WNT5A during cartilage development and in disease. Matrix Biol 2013, 32:252-264

doi:10.1186/ar4599

Cite this article as: Bougault et al:: Protective role of frizzled-related protein B on matrix metalloproteinase induction in mouse chondrocytes. Arthritis Research \& Therapy 2014 16:R137. 